\title{
Microbial Malic Acid Production: Exploring New Avenues of Synthesizing a Commercially-Valuable Chemical
}

\section{Thomas P West*}

Department of Chemistry, Texas A\&M University-Commerce, Commerce, TX 75429-3011, USA

\begin{abstract}
In tMalic acid is a commercially-valuable organic acid that has a variety of uses. The production of malic acid from various types of biomass is being explored to a limited extent. New avenues of producing this commercially-valuable chemical by biomass-based microbial bioconversion need to be investigated. There is an opportunity to determine which avenue of microbial bioconversion is the most efficient in synthesizing this industrially-important organic acid from biomass or processing coproducts.
\end{abstract}

Keywords: Malic acid; Agricultural biomass; Crude glycerol; Microbial bioconversion

\section{Commentary}

New avenues of synthesizing the commercially-useful organic acid malic acid from biomass or processing coproducts need to be sought. Malic acid has a variety of commercial uses including as an acidulant in foods and beverages. Malic acid can also be utilized for metal cleaning, textile finishing and pharmaceuticals [1]. A polymeric version of malic acid, namely polymalic acid, may be useful in the production of biodegradable polymers [2,3]. Although malic acid was originally extracted from apple juice, it is currently synthesized by the hydration of maleic acid [1]. Annually, approximately 40,000 metric tons of malic acid is produced worldwide [1]. It has been reported that the retail price of a pound of malic acid ranges from $\$ 1.80$ to $\$ 2.00$ [1]. Considering the price of malic acid per pound, the use of green chemistry approaches to synthesize malic acid from low value biomass or processing coproducts could substantially reduce its price. A reduction in its price will likely increase its use in various food or non-food products.

There have been a number of recent studies that demonstrated that malic acid or polymalic acid can be synthesized by biobased microbial conversion [2,3]. It was found that a number of Aureobasidium pullulans strains were capable of producing polymalic acid from alkaline peroxide-treated corn fiber and wheat straw [2]. Another recent study indicated that a mutant strain of A. pullulans could be used to produce polymalic acid from glucose [3]. The polymalic acid produced by the fungal mutant strain was acid-hydrolyzed to form malic acid [3]. Malic acid could also be produced by strains of the fungus Aspergillus grown on the corn-based ethanol coproduct thin stillage [4]. A new study which utilized a metabolic engineered strain of the filamentous soil bacterium Thermobifida fusca showed that the strain could ferment cellulose and corn stover into malic acid [5]. As global biodiesel production continues to increase, a surplus of the biodiesel coproduct crude glycerol has resulted and lowered the price of crude glycerol to about $\$ 0.01 /$ pound [6]. A recent study has found that crude glycerol can be utilized by three strains of Aspergillus niger to produce malic acid [7]. Other fungi or yeast may also be able to utilize crude glycerol to synthesize malic acid.

Overall, the opportunity exists to use low value biomass or processing coproducts such as crude glycerol or thin stillage to synthesize the commercially-valuable chemical malic acid. From a "green chemistry" perspective, it could help reduce the reliance on petroleum-based chemicals to synthesize malic acid. Therefore, it will be necessary to explore new microbial-based approaches that will allow malic acid to be produced efficiently from various types of biomass and processing coproducts.

\section{References}

1. Mondala $\mathrm{AH}$ (2015) Direct fungal fermentation of lignocellulosic biomass into itaconic, fumaric and malic acids: Current and future prospects. J Ind Microbiol Biotechnol 42: 487-506.

2. Zou X, Zhou Y, Yang ST (2013) Production of polymalic acid and malic acid by Aureobasidium pullulans. Biotechnol Bioeng 110: 2105-2113.

3. Leathers TD, Manitchotpisit $P(2013)$ Production of poly ( $\beta$-L-malic acid) (PMA) from agricultural biomass substrates by Aureobasidium pullulans. Biotechnol Lett 35:83-89.

4. West TP (2011) Malic acid production from thin stillage by Aspergillus species Biotechnol Lett 33: 2463-2467.

5. Deng Y, Mao Y, Zhang X (2016) Metabolic engineering of a laboratory-evolved Thermobifida fusca muC strain for malic acid production on cellulose and minimal treated lignocellulosic biomass. Biotechnol Prog 32: 14-20.

6. Dobson R, Gray V, Rumbold K (2012) Microbial utilization of crude glycerol for the production of value-added products. J Ind Microbiol Biotechnol 39: 217-226.

7. West TP (2015) Fungal biotransformation of crude glycerol into malic acid. Z Naturforsch 70c: 165-167.
*Corresponding author: Thomas P West, Department of Chemistry, Texas A\&M University-Commerce, Commerce, TX 75429-3011, USA, Tel: 903 8865399; Fax: 903-468-6020; E-mail: Thomas.West@tamuc.edu

Received May 27, 2016; Accepted June 30, 2016; Published July 10, 2016

Citation: West TP (2016) Microbial Malic Acid Production: Exploring New Avenues of Synthesizing a Commercially-Valuable Chemical. J Microb Biochem Technol 8: 321. doi: 10.4172/1948-5948.1000303

Copyright: (C) 2016 West TP. This is an open-access article distributed under the terms of the Creative Commons Attribution License, which permits unrestricted use, distribution, and reproduction in any medium, provided the original author and source are credited. 